\title{
Medical students' experiences of resuscitation and discussions surrounding resuscitation status
}

This article was published in the following Dove Press journal:

Advances in Medical Education and Practice

\section{Asha R Aggarwal lqbal Khan}

Department of Medical Education, Northampton General Hospital, Northampton, UK
Correspondence: Asha R Aggarwal Department of Medical Education, Northampton General Hospital, Cliftonville, Northampton NNI 5BD, UK Tel +44 I604545448 Email asha.aggarwal@doctors.org.uk
Objectives: In the UK, cardiopulmonary resuscitation (CPR) should be undertaken in the event of cardiac arrest unless a patient has a "Do Not Attempt CPR" document. Doctors have a legal duty to discuss CPR with patients or inform them that CPR would be futile. In this study, final-year medical students were interviewed about their experiences of resuscitation on the wards and of observing conversations about resuscitation status to explore whether they would be equipped to have an informed discussion about resuscitation in the future.

Methods: Twenty final-year medical students from two medical schools were interviewed about their experiences on the wards. Interviews were transcribed verbatim, and thematic analysis was undertaken.

Results: Students who had witnessed CPR on the wards found that aspects of it were distressing. A significant minority had never seen resuscitation status being discussed with a patient. No students reported seeing a difficult conversation. Half of the students interviewed reported being turned away from difficult conversations by clinicians. Only two of the twenty students would feel comfortable raising the issue of resuscitation with a patient.

Conclusion: It is vital that doctors are comfortable talking to patients about resuscitation. Given the increasing importance of this aspect of communication, it should be considered for inclusion in the formal communication skills teaching during medical school.

Keywords: undergraduate, communication, DNACPR, palliative care, end of life care

\section{Background}

Cardiopulmonary resuscitation (CPR) is the treatment that attempts to restart the heart in the event of a cardiac arrest. It involves delivery of chest compressions, electric shocks, drugs, and ventilation of the lungs. If successful, the patient will most likely require care in an intensive care unit after circulation is restored, and complications such as rib fractures are common. ${ }^{1}$ Currently, $18 \%$ of those who have a cardiac arrest in hospital survive to be discharged home. ${ }^{2}$

CPR was initially developed as a treatment for acute cardiac arrest secondary to a myocardial infarction. ${ }^{3}$ With increasing levels of training in CPR and dedicated hospital "crash teams," the use of CPR has gradually become more widespread, and CPR can often be attempted when the heart stops from other, less treatable causes. ${ }^{4}$

In the UK, the default position is that all patients are "for CPR" unless the decision that CPR would be inappropriate is taken in advance. This takes the form of a Do Not Attempt CPR (DNACPR) document. Resuscitation status is ultimately a medical decision, but in situations where the balance between risk and benefits is not clear, 
the wishes of the patients are key. This decision must be communicated sensitively. If this is not done in a considered way, a breakdown of trust between the patients and their doctors can occur, leading to complaints and distress for the patients and their family. ${ }^{5}$ Alternatively, if discussions are avoided altogether, patients may be deprived of a peaceful and dignified death.

The Tracey judgment was passed in 2014, in a case against a National Health Service hospital for a DNACPR implemented without patient consultation. ${ }^{7}$ The Court of Appeal ruled that DNACPRs potentially deprive a patient of life-sustaining treatment, and therefore, doctors have a "duty to consult" unless the discussion will cause a psychological or physical harm. The ruling acknowledged that while a patient cannot demand CPR if the clinician feels that it would be inappropriate, the patient should still be informed that the decision has been taken.

Furthermore, there has recently been widespread media coverage of DNACPR decisions. Often these articles are highly critical of doctors for "imposing" DNACPR forms on patients without explaining this to the patient or asking the family for consent. ${ }^{6}$

In response to the Tracey judgment and to increasing public awareness of this issue, the Resuscitation Council updated their guidelines in 2016 on "Decisions Relating to Cardiopulmonary Resuscitation" in order to "ensure highquality communication, decision-making, and recording in relation to decisions about CPR."

In the guideline, the Resuscitation Council states that the responsibility of discussing and completing the DNACPR rests with the most senior decision-maker (in most cases, the hospital consultant or general practitioner). However, local hospital guidelines vary widely with relation to who may complete the documentation, ${ }^{9}$ with any doctor being able to sign the form in some hospitals. Even when the consultant must be the signatory on the form, it is often ward juniors who have the greatest rapport and contact with the patient and their relatives so it may often fall to them to conduct discussions regarding resuscitation. Furthermore, work is being undertaken to ensure that discussions surrounding CPR are routine on admission. ${ }^{10}$ The admission clerking and hence CPR status discussion may be carried out by any doctor from graduation onwards.

In this study, final-year medical students from two medical schools were interviewed about their experiences of CPR and of observing DNACPR discussions. The purpose of this study was to evaluate whether final-year medical students have the experience needed to have an informed discussion with patients or relatives about CPR and whether they would feel comfortable communicating about DNACPRs. This is vital given that they may be required to have these conversations soon after graduation.

\section{Methods}

A proposal and a protocol for the project were submitted to the Northampton General Hospital Research and Development office. The project was deemed to be classified as a "service evaluation," and therefore, ethical approval was not required.

\section{Sample selection}

Final-year medical students from Oxford and Leicester Medical Schools were recruited while on placement at Northampton General Hospital. Permission to interview students had been granted by each medical school. Students were recruited both by e-mail and in person at teaching sessions. All students who were approached about the study took part.

Participants were consented verbally and were assured that their responses would be anonymized. In total, twenty students took part in the study.

\section{Data collection}

A semi-structured interview was carried out in a neutral space regarding the students' experience of resuscitation and DNACPR discussions. Interview questions were composed by the interviewer and a senior consultant prior to interviews commencing. The interviews typically lasted 15 minutes and were recorded on a portable voice-recorder. All interviews were conducted by the same researcher. Questions were revisited based upon the analysis, but no alterations were required. The primary researcher then transcribed the anonymized interviews on a password-protected personal computer.

\section{Data analysis}

The aim was to gain an understanding of the students' experiences surrounding CPR and DNACPR discussions. In order to do this, thematic analysis of the interview transcripts was undertaken. The primary researcher read the transcripts and coded the text. Codes were verified by the second researcher. Connections were then made in order to produce themes. Representative quotations for each theme were noted and tabulated.

\section{Results}

Twenty final-year medical students took part, ten from Oxford Medical School and ten from Leicester Medical School. Students from both medical schools were at the same stage of training. Due to the rotational nature of medical school 
timetables, placements that the students had completed were variable.

The themes fell into two important categories:

1. Experiences on the wards

2. How they would feel about discussing CPR with a patient in the future

\section{Experience on the wards Variable exposure to CPR}

All students had completed Basic Life Support (BLS) and were due to complete Intermediate Life Support (ILS) before the end of the year, if it had not already been completed.

Of the twenty students interviewed, eleven had witnessed CPR during their training.

If you're lucky and you're following the right person. (Student 2)

I have been there but I couldn't really see much and you're a medical student so you get pushed out of the way. So you don't really get involved. (Student 6)

\section{The realities of CPR}

Students reflected on the differences between their BLS/ILS training and the realities of CPR.

More frantic and less organized, but you can still identify the main bits and pieces. (Student 1)

If the person leading it is in charge and has a good presence and coordinates it well then the chaos turns into calmness if that makes sense, and the job gets done. (Student 3)

I remember seeing the paramedic doing chest compressions and thinking "wow, someone's actually doing chest compressions" because I'd never seen it, but it's really quite brutal because the whole chest wall was bending and I can see how they break ribs now. It was more brutal than I thought. They did stick to it [ALS protocol] but there were just all of these other emotional and stressful factors. (Student 10)

I felt it was quite intrusive in a way in which, had the patient been conscious, they might have been quite shocked about. (Student 16)

\section{Variable teaching on DNACPRs}

Teaching on the subject of DNACPR discussions was variable - one medical school had covered DNACPRs in the ethics part of the course, but there had not been any communication-related training. At the other medical school, a few students had received opportunistic teaching on the subject on a District General Hospital placement that would not have been given to all students at their medical school.

I wouldn't say we've had any training in how to do it. We've been over the practicalities rather than the communication side of things, which is what worries me. (Student 8)

We had some teaching in palliative care about who to resuscitate and who not to resuscitate but not a huge amount. The main thing I remember is that CPR has a very low probability of success. (Student 13)

I think it [ethics teaching] wasn't really taken from a practical standpoint - our ethics course if done by a guy who is amazing but definitely from a theoretical basis so it wasn't really geared toward what to practically do or say. Maybe something more end-goal directed would be more useful. (Student 10)

\section{Watching discussions about CPR}

Sixteen of the twenty students interviewed had been present for discussions about CPR.

It was ingrained into the team's ward rounds. Every patient they didn't forget to do it or think about it, it was always considered. (Student 7)

I've never seen ... a contentious one. It's always been relatively self-explanatory so it hasn't needed to be very formal. (Student 15)

Often the consultant had quite a preliminary discussion about it on the ward round then left lots of things to be done later, like talking to the family and things. (Student 8)

Ten of the twenty students interviewed described being turned away from difficult discussions regarding CPR while on the wards. All of the students felt that it was important to see these discussions take place. However, the vast majority felt that it was appropriate for them to be excluded.

Obviously you want to see the difficult ones, because when a difficult one comes around it's good to have seen how someone else dealt with it. (Student 15)

I have been asked to leave when the doctor was discussing these things with the family ... it was more asked not to come along rather than to leave the room ... I guess they thought it might make their job easier? (Student 6) 
I've been turned away a few times, just simply giving the patient space. I was fine with it, because I've seen it more than I've not been allowed to see it. (Student 18)

I think medical students should be ... given more opportunities to see breaking bad news and stuff ... I think there's enough things that are really daunting when you start working ... it's unnecessary to have to be involved in that kind of thing suddenly when you could have been involved as a medical student. (Student 1)

One student explained that sometimes it was his own decision not to observe the discussions.

Yeah there are times when I've hung back, sometimes out of my own volition. I suppose sometimes it just feels strange being an onlooker to something that personal. I know it's important for us to see, but ... it doesn't feel right to be just there watching. (Student 12)

Students felt that at times, patient discomfort with the student watching was assumed by the doctors.

Maybe saying to the patient, this is what we'll be discussing and ask whether they are comfortable with this extra person. Because most of the time patients are really accommodating to students because they know we need to learn. (Student 4)

I think if we do get sent away, they should go through or simulate what they went through. But usually they're really busy so they don't have time. (Student 17)

\section{Thoughts on the discussions they had seen}

I thought it would be quite distressing for me; I'll be completely honest. I thought it was going to be a horrible conversation, I thought the family were going to be distressed and reject it. But it's not like that. (Student 15)

You hear really bad things about how DNACPRs are imposed on people because it's a medical decision but actually I was impressed with how it was communicated ... (Student 14)

One student had talked to multiple patients about DNACPRs on a community hospital placement, though had never seen it being done prior to this.

It's not something I ever expected to have to do as a student. The first time, I actually missed it out and I went back and presented the patient ... she said, "Did you ask about this" ... and sent me off on my way ... to ask them. So it was a bit strange, but it got better after that. (Student 4)

\section{Feelings about conducting future discussions \\ How they would feel about raising the issue of CPR with a patient or a relative}

I would feel that I was muddling through it if I had to do

it. (Student 15)

I feel confident with communication skills and handling the range of emotions ... but we haven't had any specific training on this sort of thing and I'd be worried about putting my foot in it. (Student 10)

Not comfortable on my own. I guess I could describe the nuts and bolts of the process ... but I would need support. (Student 19)

Only two of the twenty students interviewed felt comfortable raising the issue of resuscitation with patients. Of these, one student felt confident, having seen the discussion take place multiple times, and the student who had discussed CPR on her placement in a community hospital was also confident to speak to patients and their relatives about CPR in the future.

One other student felt confident to ask patients about their views, but not to explain a medical decision for a DNACPR.

\section{What could help them to feel more confident}

Students were asked what kind of teaching or training would help them to be comfortable in bringing up the subject of resuscitation with a patient.

We would need to have a practice session, definitely. Not necessarily with real patients, just with simulated patients to say the words and getting it out in a fluid way because in that kind of discussion, the way you say it has a big impact on how they feel about it. So I think having a bit of practice at getting your mouth around the words would help. (Student 4)

I suppose you could see it 100 times and you still wouldn't feel ready. I think I'm as ready now as I would be if I saw it another 50 times. But you just need that confidence to make that step. And I'm sure when you've done it once, the subsequent times would be much easier. (Student 2)

It's definitely necessary to have a session in that kind of setting where you can practice and it's set up in a safe space ... and you can reflect on how each of you are doing. Because just watching doesn't really give you a feeling of how those discussions go. (Student 14) 
In your head it's easy to think "this is the conversation I'd have, this is how I'd put things,' but when you go to say it in real life, it doesn't come out the same way. So we need to practice saying it. (Student 11)

\section{Why they feel wary of entering the conversation unprepared}

While they acknowledged that medical school cannot actively prepare them for every situation, the students explained why they felt that specific teaching in this area would be useful.

It's obviously quite a difficult and emotive topic where different members of the same family can potentially have very different opinions. I think there's a lot of misunderstanding as well. (Student 6)

I wouldn't feel fully prepared to answer any questions that they may have, and I think that would be the thing that would detract me most from doing it. (Student 2)

It's about knowing a bit more about talking to people about what can be demanded of doctors and what can't and what the likelihood of success will be. (Student 10)

\section{Attitudes toward death and dying}

A few students talked about doctors' attitudes toward death and dying in the context of why talking to patients about DNACPRs can be difficult.

I think people see doctors and doctors see themselves as there to cure, right? That's our job in a huge way so the discussion of "do not resuscitate" feels like going against our duty as a doctor perhaps? It feels like we are letting someone down. (Student 9)

I have this may be very unrealistic expectation that patients come in, they're ill, we treat them, they all get better and they all go home, and we don't like to go there [death], it doesn't even pop up on my thought process of things to think about when people come into hospital. (Student 4)

If you've got someone that's older and had their whole life and all that experience and things, talking to them about the end of their life and making decisions about that seems kind of a strange thing to do for someone that's young and just starting out in their job and stuff. It's almost a funny reversal. (Student 12)

\section{Discussion}

This is the first UK-based qualitative study to explore the experiences and attitudes of final-year medical students with regard to resuscitation and DNACPR discussions.
One significant finding was that almost half of the students interviewed had never seen CPR being performed in real life. This could be for a number of reasons. Arrest calls are becoming less frequent in hospitals, ${ }^{2}$ with a greater emphasis on recognizing the deteriorating patient before arrest occurs and an increasing number of patients with DNACPRs as the population ages. ${ }^{3}$

One could argue that the mannequin-based training in formal courses such as BLS/ILS/Advanced Life Support does not prepare the learner for the realities of an arrest call. This could prevent the students having a fully informed discussion about CPR in the future. As demonstrated in the interviews, the students who had experienced an arrest call were shocked by the sight and sound of the rib fractures often associated with CPR and by the chaotic nature of the situation. A study in 2010 asked geriatric registrars to recount their best and worst memories of CPR and DNACPR discussions. ${ }^{11}$ Many of the situations recounted in this paper, such as resuscitation of young patients and resuscitation of patients for whom CPR was inappropriate, demonstrate that the reality of arrest calls goes far beyond what was learned in formal resuscitation courses.

At one medical school, a session on DNACPR decisions had been included in ethics teaching but was deemed by the students to be more theoretical than practical. At the other medical school, no formal teaching on the subject had been provided. Neither medical school had incorporated the discussion of resuscitation decisions in communication skills teaching.

Students had variable exposure to discussions surrounding DNACPRs on the wards, with four of twenty students having never observed this. While they had not yet come to the end of their final year, embarking on these discussions without any training or ever having seen them would be daunting.

Given that we are moving toward a routine discussion of CPR status on or soon after admission, ${ }^{10}$ it is interesting that some students have never seen this conversation take place. It may be that the "clerking and signs" culture ${ }^{12}$ of medical students who are geared toward assessment discourages students from staying with the clinical team after ward rounds, which is when these discussions may take place. In addition, an increasing amount of scheduled teaching may take students away from the wards where this experience would be gained. ${ }^{13}$

Finally, half of the students interviewed reported that doctors had turned them away from difficult discussions surrounding CPR on the wards. While the students acknowledged that having fewer people in the room could be benefi- 
cial for the patient in these situations, the students missed out on observing a key part of clinical practice. None of the students interviewed had ever witnessed a difficult or controversial discussion about resuscitation status with a distressed patient or his/her family. This is not an uncommon situation, and being equipped with the adequate communication skills to deal with this is vital. Watching a senior and competent clinician deal with a difficult DNACPR discussion would go some way acquiring the necessary skills.

All but one of the students who had been turned away from difficult conversations said that it was the clinician who stopped them from observing, rather than the patient or staying away of their own accord. An interview-based study ${ }^{12}$ of twenty-one FY1 doctors found that while sometimes as students they had been kept away from dying patients or difficult conversations, mostly they avoided the situations themselves. This finding conflicts with the results of this study. It may be that dying patients make medical students more uncomfortable than complex discussions with patients or families.

There is a lack of evidence regarding how patients feel about medical students observing sensitive discussions. This is an area that warrants further research, as it has become an accepted practice for students to be excluded. If patients and their relatives are comfortable with students observing, it would be interesting to know the reasons behind this cultural norm.

The most significant finding is that only two of the students interviewed would feel comfortable to raise the issue of CPR with patients or their relatives, of whom one had already conducted conversations about CPR. The main reasons for this discomfort were awareness of the potential emotional reaction to the subject and a feeling that they would not be able to answer questions that the patients or their relatives may ask. All students interviewed felt that the subject of DNACPRs was something that warranted specific teaching within the medical school curriculum. The students felt that watching discussions was helpful, but practice "saying the words" and responding to questions were the main outcomes that they wanted from a session.

The role of educational interventions to improve DNACPR discussions has been the subject of multiple studies. In particular, Szmuilowicz et al designed a multimodality intervention including practicing communication skills and an e-learning package for a group of doctors after graduation. Their skills, as measured by a checklist, were significantly better than the control group both at a 2-month ${ }^{14}$ and 1-year follow-up. ${ }^{15}$ Interestingly, in the year of clinical experience between the two follow-up visits, the measured skills of the control group did not improve. This would suggest that rigorous communication skills training in this area can lead to long-lasting skills, which cannot be gained "on the job."

Students felt that one key reason that DNACPR discussions were difficult was fear from both patients and doctors of acknowledging and discussing death. Gaps in undergraduate palliative care and end-of-life communication have been well documented, ${ }^{16}$ and a concerted effort is being made to rectify this. As palliative care becomes more prominent in undergraduate curricula, awareness of death and fear of discussing it with patients may improve.

A feeling of discomfort surrounding DNACPR discussions is not restricted to medical students. A comprehensive paper in 2016, ${ }^{10}$ which included both a meta-analysis and focus-group interviews, showed that DNACPR discussions are an area that most doctors find difficult, and it was felt by all, including consultants, that specific training would be advantageous.

One limitation of this study is that the participants were from just two medical schools. This means that the experiences recounted by the interviewees may not be a representative of medical students across the country. Palliative care integration into medical school curricula varies widely, ${ }^{16}$ and hence, comfort in discussing end-of-life issues may be better elsewhere.

Furthermore, the medical students still had approximately 2 months of placements remaining before their final exams and 6 months before graduation. Therefore, they may yet have specific training on discussing CPR with patients before they start work as doctors.

Given the outcome of the Tracey Case in 2014, ${ }^{7}$ it is clear that communication regarding CPR status must be of the highest order. This is an area that many practicing doctors feel is difficult. Given the potential consequences of poor communication in these situations and the proven value of educational interventions on this subject, specific training on DNACPR discussions should be incorporated into undergraduate medical curricula. The students interviewed felt that their communication skills teaching was, in general, very good, and the inclusion of DNACPRs into one of these sessions would be a sustainable way of improving their skills in this area.

\section{Conclusion}

Final-year medical students from two medical schools describe variable exposure to CPR and DNACPR discussions during their clinical attachments. The vast majority would feel uncomfortable bringing up the subject of CPR with patients or their relatives. Given the increasing importance 
of this aspect of communication, it should be considered for inclusion in the formal communication skills teaching nationwide.

\section{Disclosure}

The authors report no conflicts of interest in this work.

\section{References}

1. Hoke RS, Chamberlain D. Skeletal chest injuries secondary to cardiopulmonary resuscitation. Resuscitation. 2004;63:327-338.

2. Nolan JP, Soar J, Smith GB, et al. Incidence and outcome of in-hospital cardiac arrest in the United Kingdom National Cardiac Arrest Audit. Resuscitation. 2014;85:987-992.

3. National Confidential Enquiry into Patient Outcome and Death. Time to Intervene? A Review of Patients Who Underwent Cardiopulmonary Resuscitation as a Result of an In-Hospital Cardiopulmonary Arrest NCEPOD; 2012. Available from http://www.ncepod.org.uk/2012cap. html. Accessed November 15, 2017.

4. Kouwenhoven WB, Jude JR, Knickerbocker GG. Closed-chest cardiac massage. JAMA. 1960;173:1064-1067.

5. Gorton AJ, Jayanthi NV, Lepping P, Scriven MW. Patients' attitudes towards "do not attempt resuscitation" status. J Med Ethics. 2008;34:624-626.

6. The Telegraph - "Exclusive: 'Unforgivable' failings in end-of-life care revealed as 40,000 dying patients subject to secret 'do not resuscitate' orders every year"; 2016. Available from: http://www.telegraph.co.uk/ news/2016/05/01/unforgivable-failings-in-end-of-life-care-revealed40000-dying-p/. Accessed January 20, 2017.
7. R (Tracey) v Cambridge University Hospitals NHS Foundation Trust \& Ors. EWCA 3860 Civ 822; 2012. Available from https://www.judiciary. gov.uk/wp-content/uploads/2014/06/tracey-approved.pdf. Accessed November 15, 2017.

8. Resuscitation Council (UK) Decisions relating to Cardiopulmonary Resuscitation (3rd edition - 1st revision); 2016. Available from: https://www. resus.org.uk/dnacpr/decisions-relating-to-cpr/. Accessed January 20, 2017.

9. Freeman K, Field RA, Perkins GD. Variation in local trust Do Not Attempt Cardiopulmonary Resuscitation (DNACPR) policies: a review of 48 English healthcare trusts. BMJ Open. 2015;5:e006517.

10. Perkins GD, Griffiths F, Slowther AM, et al. Do-not-attempt cardiopulmonary-resuscitation decisions: an evidence synthesis. Health Serv Deliv Res. 2016;4(11).

11. Myint PK, Rivas CA, Bowker LK. In-hospital cardiopulmonary resuscitation: trainees' worst and most memorable experiences. QJM. 2010;103:865-873.

12. Gibbins J, McCoubrie R, Forbes $\mathrm{K}$. Why are newly qualified doctors unprepared to care for patients at the end of life? Med Educ. 2011;45:389-399.

13. Crumlish CM, Yialamas MA, McMahon GT. Quantification of bedside teaching by an academic hospitalist group. J Hosp Med. 2009;4:304-307.

14. Szmuilowicz E, Neely KJ, Sharma RK, Cohen ER, McGaghie WC, Wayne DB. Improving residents' code status discussion skills: a randomized trial. J Palliat Med. 2012;15:768-774.

15. Wayne DB, Moazed F, Cohen ER, Sharma RK, McGaghie WC, Szmuilowicz E. Code status discussion skill retention in internal medicine residents: one-year follow-up. J Palliat Med. 2012;15:1325-1328.

16. Walker S, Gibbins J, Barclay S, et al. Progress and divergence in palliative care education for medical students: a comparative survey of UK course structure, content, delivery, contact with patients and assessment of learning. Palliat Med. 2016;30(9):834-482.
Advances in Medical Education and Practice

\section{Publish your work in this journal}

Advances in Medical Education and Practice is an international, peerreviewed, open access journal that aims to present and publish research on Medical Education covering medical, dental, nursing and allied health care professional education. The journal covers undergraduate education, postgraduate training and continuing medical education

\section{Dovepress}

including emerging trends and innovative models linking education, research, and health care services. The manuscript management system is completely online and includes a very quick and fair peer-review system. Visit http://www.dovepress.com/testimonials.php to read real quotes from published authors. 